\title{
sciendo DETECTION AND RECORDING OF ACOUSTIC EMISSION IN DISCRETE IGBT TRANSISTORS
}

doi:10.2478/mape-2018-0004

Date of submission of the article to the Editor: 03/2018

Date of acceptance of the article by the Editor: 07/2018

MAPE 2018, volume 1, issue 1, pp. 27-31

\author{
Mgr inż. Radosław Gordon \\ Mgr inż. Andrzej Dreas \\ Maritime University of Szczecin, Poland
}

\begin{abstract}
The article presents the results of experimental research, which is to show a correlation between the change of operating status of single IGBT transistor and its acoustic emission. Sensor signal was obtained with oscilloscope in order to further process it digitally and determine possibility of the damage to the element based on registered acoustic signal.
\end{abstract}

Keywords: IGBT Modules, IGBT Transistor, Acoustic Emission.

\section{INTRODUCTION}

Power industrial equipment and electronic systems cannot exist without discrete semiconductor circuits. Particularly rapid development of this kind of systems in recent years has been noticed in electronics and signal control systems with high output power. Control of those systems is theoretically relatively simple, but by switching high currents and voltages in semiconductors that often require many switching per unit time, it makes it really difficult in practical applications. The occurrences inside the semiconductors structure are often at borderline between classical and quantum physics. Therefore watching what is happening inside such structures is a quite big challenge for designers, producers and users.

There are many methods of non-invasive observation of occurrences in semiconductors elements and their description, such as observation of currents and voltages, both input and output, temperature changes etc. and their profound analysis (Kärkkäinen, 2015), (Luowei Zhou and Sun, 2013).

Another very interesting solution is to test the systems with forbidden status in normal operations of IGBT bridges, made in the idle state of motor (Yeke et al., 2016).

The knowledge of possible microdamages to the individual IGBT transistors or whole modules increasingly affects the safety of equipment and people. Among the applications of IGBT technology the following can be mentioned : control and operation of wind turbine generators (Wang et al., 2016), (Zhu et al., 2011), urban transport, control of subway motors, trains, trolleybuses and trams (Yeke et al., 2016), control of tracer motors in jet controls and electric network on ships or offshore units (Kozak et al., 2016).

This article presents an analysis of the acoustic emission of the popular IGBT transistor using the Vallen acoustic emission sensor. The research has been conducted since 2016 at the Institute of Electrical Engineering and Automation of the Maritime University and is constantly confronted with the current state of the art on this subject in the world. This type of research is conducted also by the team of Finnish scientists with ABB Group (Kärkkäinen, 2015), (Kärkkäinen and Talvitie, 2014). The research description conducted by this center as well as work (Kärkkäinen and Talvitie, 2014) do not answer the questions that arise during the analysis of this problem. Because of the specifics of this research, the proper equipment and measuring methods were used according to the needs of this system for the acquisition of data and results analysis. 
The results of this research are intended to show that received data might be useful for further processing as well as to identify failures or signals indicating significant degradation of semiconductors structure (impending damage) of an IGBT transistor.

\section{MEASURING METHOD}

A popular oscilloscope for filtering and recording digital data was used for measurements. The measuring element was Vallen's VS600-Z1 acoustic converter, which is characterized by transmission of spectrum within the range of $550-730 \mathrm{kHz}(600 \mathrm{kHz}$ ) (Vallen-Systeme GmbH data sheet). The scheme of measurement system is shown in Figure 1.

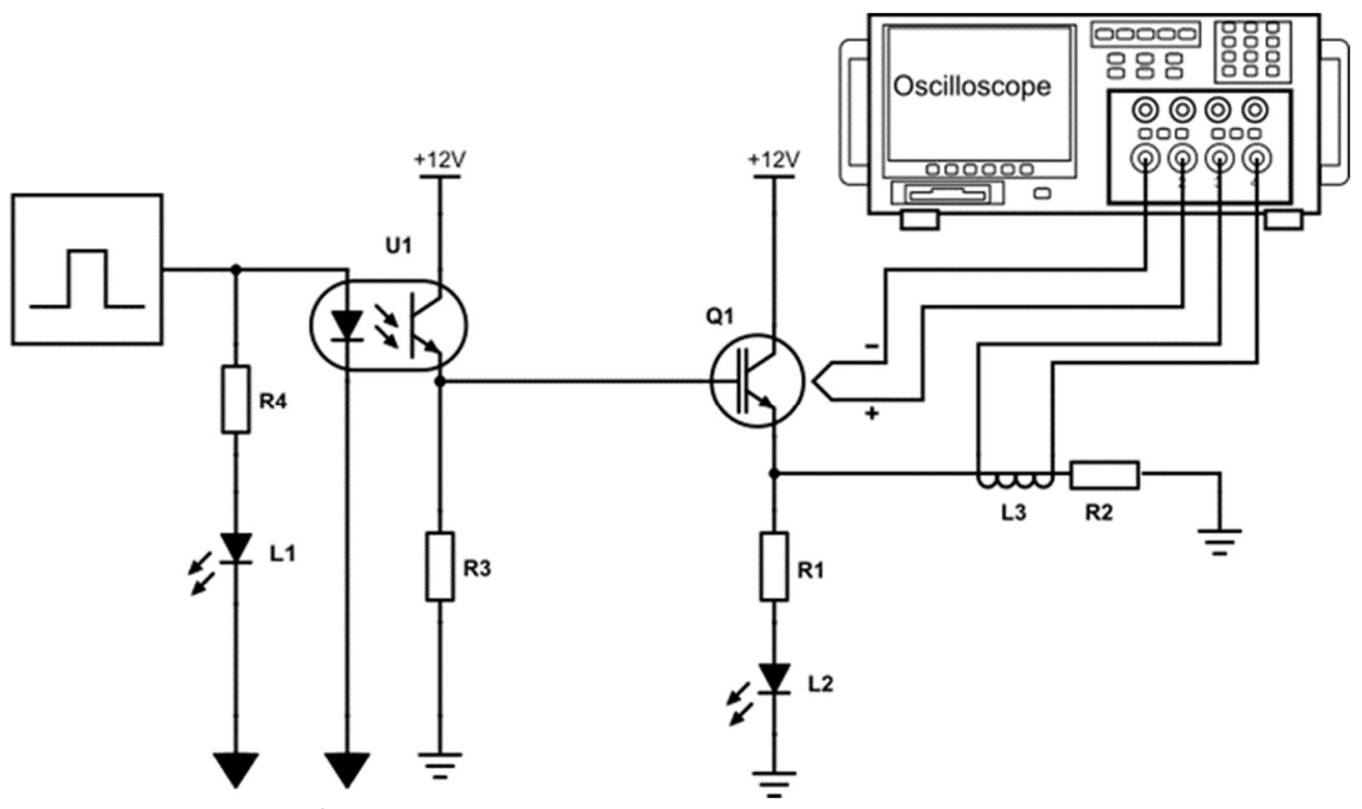

Fig. 1. Scheme of measurement system used in experiment

Transistor is controlled by generator which is separated from the gate with optocoupler. The L1 diode informs about the state at the generator output ("slow-changing" rectangular signals). The optocoupler transistor controls the gate of tested IGBT transistor. Transistor operates in two conditions: closed or open. The charge of the transistor is provided by the R2 resistor and system composed of resistor R1 and a diode denoted as L2 (small), which signals the switching of the transistor. The clamp ammeter was placed over the wire connecting the output of the emitter and R2 resistor. The ammeter gives waveforms of the current to the oscilloscope input. Signal from acoustic emission sensor is given directly to second oscilloscope channel. Figure 2 shows the example of reading from the oscilloscope.

It can be seen that signal 1 shows the current on the transistor output from clamp ammeter while signal 2 is obtained from acoustic emission sensor, which is placed directly on the surface of the IGBT transistor. 


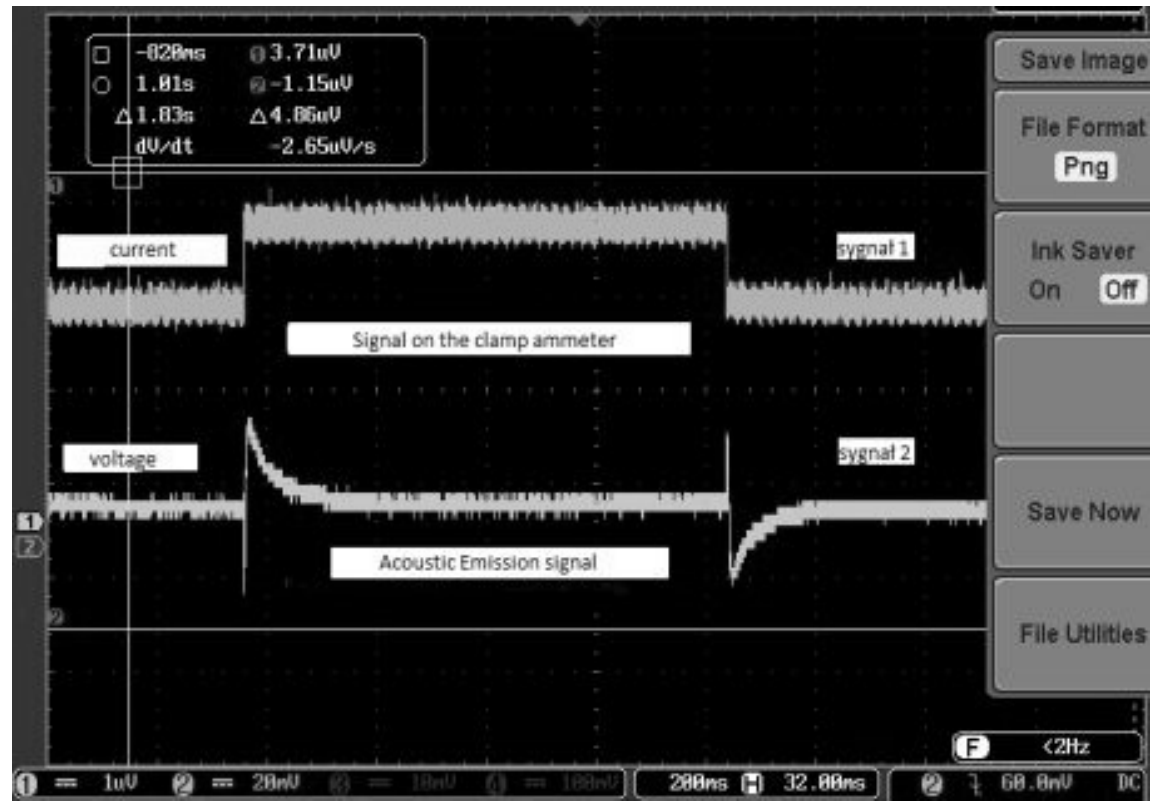

Fig. 2. Waveforms of acoustic emission and corresponding transistor current acquired on the digital oscilloscope

One of the most important factors during the measurements was proper fitting of acoustic emission sensor, which had to be placed directly above the silicon structure. Special treat was provided for preparation of contact point between silicon surface of power element and an $A E$ sensor. Appropriate contact between sensor and tested element was assured through the special grease recommended by the manufacturer of the sensor, and without it the results may vary from expected (Vallen-Systeme $\mathrm{GmbH}$ data sheet). The measurements were carried at different values of switched current and voltage. As each parameter increased, the signal recorded on the oscilloscope was also proportionally larger. Figure 3 shows the acoustic emission with higher switching frequency.

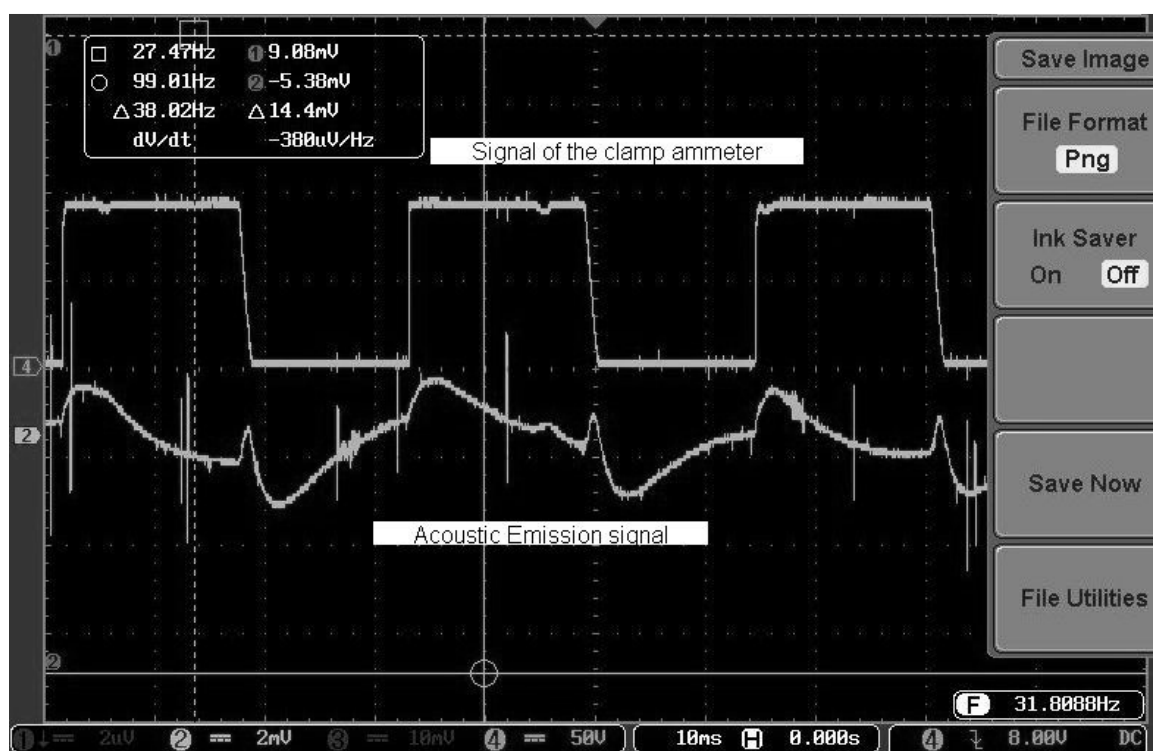

Fig. 3. Waveforms of acoustic emission at $31,8 \mathrm{~Hz}$ of switching frequency

Figure 4 shows the structure of IGBT transistor and it explains the form of signal obtained in time. By analyzing this structure, capacitances can be seen which are weak link in the transistor inner structure, and they affect the signal at the time of switching. 


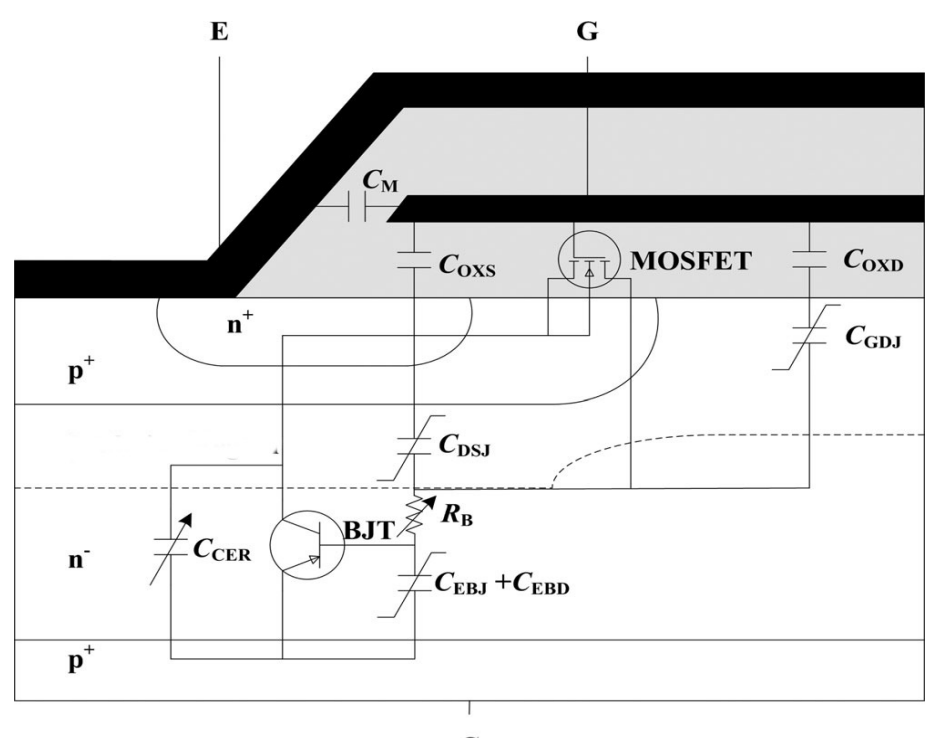

C

Fig. 4. Internal structure of IGBT transistor

Typical charging and discharging processes of parasitical capacitances of transistor can be seen in Fig. 2. Due to small currents, the signal is not smooth, but it clearly shows the capacitive response to the transistor operating when the state changes. The response is similar when switching from open status to closed status and in reverse, and that means that sensor has recorded the transistor switching.

It proves the chance of non-invasive measurements and proper detection of the transistor operating status. Moreover, the presented method can confirm the correctness of IGBT operation. With proper tools it is possible to define the parasitical capacitances of transistor, which gives further possibility of identification the inner silicone structure damages and the effects caused by the "aging" of the element. Such diagnostics allows to define when the damage to the given element would occur.

Based on Figure 4. and (Luowei Zhou and Sun, 2013) correlation between capacitance changes and voltage on individual elements of internal structure can be defined:

$$
\begin{gathered}
C_{G C}=\left\{\begin{array}{cc}
C_{O X D} & V_{C E}<V_{G E}-V_{G E(t h)} \\
\frac{C_{O X D} C_{G D J}}{C_{O X D}+C_{G D J}} & V_{C E} \geqslant \geq V_{G E}-V_{G E(t h)}
\end{array}\right. \\
C_{G C}=\frac{A_{G D} \varepsilon_{S i}}{\sqrt{2 \varepsilon_{S i}\left(V_{C E}-V_{(t h)}\right) / q / N_{B}}}
\end{gathered}
$$

where:

$C_{G C}$ - capacitance collector - emitter, consisting of capacitance in the point of contact of silicon oxide gate - drain CoxD and capacitance of saturation gate - gate drain,

$C_{G D J}$ - depending on $V_{C E}$ voltage (collector - emitter), where $A_{G D}$ is the area of the point of surface contact,

$\varepsilon_{S_{i}}$ - constant of silicon dielectric and liminal voltage gate emitter $V_{G E(t h)}$,

$N_{B}$ - area of concentration of majority carriers.

As it turns out, aforementioned formulas have the biggest influence on acoustic emission waveforms obtained on oscilloscope.

\section{CONCLUSIONS}

The possibility of defining the correlation between switching IGBT transistor and generated signals of acoustic emission was the main goal of the presented research. Acquired AE signals can be post-processed and after some analysis the status of transistor can be specified (good, 
damaged or nearly damaged). Trials of detecting of acoustic emission on radiator was made. Sensor was put close to measured transistor on its radiator. There was three types of radiators used in this experiment: steel bar, steel sheet and aluminium bar. Placement of AE sensor on the radiator was made for verification how radiator affect acoustic signal. This measurements were unsuccessfull because sensitivity of sensor was too small. There is necessity to isolate acoustic signal from noise made by other equipment. This will be the subject of the further research.

The tests showed, that switched IGBT transistor is characterized by measurable acoustic emission of signals and such signals correspond to the theoretical assumptions.

The measurements were carried for relatively small voltage values and switching currents in order to proper values recording. Increasing of currents should result in improved readings of acoustic emission sensor signals.

\section{REFERENCES}

AE- Sensor Overview, Vallen-Systeme GmbH data sheet.

Bejger, A., (2008). Analysis of acoustic emission signal frequency bands dependent on phenomena in an injector. Scientific Journals Maritime University of Szczecin

Kärkkäinen, T., Talvitie, J.P., Kuisma, M., Hannonen, J., Strom, U., Mengotti, E., Silventoinen, P (2014). Acoustic Emission in Power Semiconductor Modules-First Observations. IEEE Transactions on Power Electronics, vol. 29, no. 11, nov. 2014

Kärkkäinen, T., (2015). Observations of acoustic emission in power semiconductors. Lappeenrannan teknillinen yliopisto, Yliopistopaino, ISBN 978-952-265-912-5

Kozak, M., Gordon, R., Bejger, A. (2016). Control of squirrel-cage electric generators in a parallel intermediate DC circuit connection. Zeszyty Naukowe, Akademia Morska w Szczecinie, nr 45 (117), pp.17-22 ISSN1733-8670

Luowei Zhou, S., Sun, P. (2013). Monitoring Potential Defects in an IGBT Module Based on Dynamic Changes of the Gate Current. IEEE Transactions on Power Electronics, Vol. 28, no. 3, March 2013

Turkia, V. and Holttinen, H. (2013). Wind energy statistics of Finland - yearly report 2011.

Wang, B., Wang, X., Wang, X., Shao, C., Liu, S. (2016). Reliability evaluation of voltage-source converter-based multi-terminal direct current integrated offshore wind plants. Department of Electrical Engineering and State Key Laboratory on Electrical Insulation and Power Equipment, Xi'an Jiaotong University, IET Renew. Power Gener., 2016, Vol. 10, Iss. 6, pp. 761-766,

Yeke, L., Dawei, X., Yifan, F. (2016). Prognosis of Chip-loss Failure in High-power IGBT Module by Selftesting. Department of Electrical Engineering Tongji University Shanghai, China, 2016 IEEE

Zhu, P., Liu, Y., Roesner, R., Hao, X. (2011). Offshore Wind Converter Reliability Evaluation. In: 8th International Conference on Power Electronics - ECCE Asia May 30-June 3, 2011, The Shilla Jeju, Korea 